\title{
Atmospheric Pressure Thermal Dissociation of Phospho- and Sulfopeptides
}

\author{
Lívia S. Eberlin, ${ }^{\text {a }}$ Yu Xia, ${ }^{\text {a }}$ Hao Chen, ${ }^{\mathrm{b}}$ and R. Graham Cooks ${ }^{\mathrm{a}}$ \\ ${ }^{a}$ Department of Chemistry, Purdue University, West Lafayette, Indiana, USA \\ ${ }^{b}$ Center for Intelligent Chemical Instrumentation, Department of Chemistry and Biochemistry, Ohio \\ University, Athens, Ohio, USA
}

Several phospho- and sulfopeptides were subjected to atmospheric pressure thermal dissociation (APTD), which was effected by passing peptide ions generated by electrosonic spray ionization (ESSI) through a heated coiled metal tube. Sequence informative fragment ions including a-, b-, c-, and y-types of ions were observed with increased relative intensities under APTD compared with collision-induced dissociation (CID), performed inside the ion trap. A certain degree of preservation of phosphate and sulfate ester moieties was observed for some fragments ions under APTD. The neutral fragments generated outside the mass spectrometer were further analyzed via on-line corona discharge to provide rich and complementary sequence information to that provided by the fragment ions directly obtained from APTD, although complete losses of the modification groups were noted. Improved primary sequence information for phospho- and sulfopeptides was typically obtained by analyzing both ionic and neutral fragments from APTD compared with fragment ions from CID alone. Localization of the modification sites of phospho- and sulfopeptides was achieved by combining the structural information acquired from APTD and CID. (J Am Soc Mass Spectrom 2008, 19, 1897-1905) (c) 2008 American Society for Mass Spectrometry

$\mathrm{P}$ rotein identification and characterization, which has become one of the central activities in proteomics, relies heavily on the information that can be obtained from gas-phase dissociation of peptide ions [1]. For this reason, there has been a strong interest in developing and improving dissociation methods over the past two decades. The most commonly used method to dissociate peptide ions is still collision-induced dissociation (CID), which involves energetic collisions between ions and inert neutral bath molecules [2]. Structurally informative amide bond cleavages are generally observed under CID conditions, giving rise to $\mathrm{b}$ - and y-type ions. While CID has been quite successful in identifying the primary sequence of peptides and hence of proteins, it, however, often fails to provide complete sequence information due to the existence of strongly preferred fragmentation channels [2]. Other than CID, a wide variety of approaches has been developed and examined for dissociating gas-phase peptide ions. For example, surface induced dissociation (SID) has been applied to peptide and protein ion dissociation [3]. Photodissociation techniques, including infrared multiphoton dissociation (IRMPD) [4, 5], blackbody infrared dissociation (BIRD) [6], and singlephoton UV dissociation $[7,8]$ also show potential in providing useful structure information and thermochemical data. Electron capture dissociation (ECD) $[9,10]$ and electron-transfer dissociation (ETD) [11, 12] of multiply

Address reprint requests to Dr. R. G. Cooks, Department of Chemistry, Purdue University, West Lafayette, IN 47907-1393, USA. E-mail: cooks@ purdue.edu charged peptide or protein ions demonstrate unique features, with more sequence independent fragmentation preserving labile post-translational modifications (PTMs) than CID in most cases.

All the above dissociation techniques can be applied more or less successfully to identify the primary sequence of a peptide or a protein. This makes it an important issue that needs to be addressed to characterize proteins with PTMs by mass spectrometry (MS), considering the critical roles they play in biological systems [1, 13]. For example, reversible protein phosphorylation, the most widely observed PTM, plays key regulatory roles in cellular processes and in intracellular signal processing, resulting in countless functional consequences [14-16]. Tyrosine-sulfation, the most frequently observed sulfation within proteins, has been reported to be involved in various biological events such as mediation of inflammatory leukocyte adhesion, chemokine receptors, and modulation of blood coagulation cascade [17]. In the case of structural characterization of phosphopeptides [18, 19] and sulfopeptides [20-22], the primary sequence of a peptide is typically acquired through examination of the fragment ions generated by CID. Since sequence-specific backbone fragmentation is frequently suppressed upon CID of deprotonated phosphopeptides due to facile loss of the phosphate groups [23], CID in the negative ion mode is useful for phosphopeptide detection, but sequencing of phosphopeptides is commonly done in the positive ion mode [24, 25]. Localization of phosphorylation or sulfation sites via CID resorts to the detection of pairs of 
peaks with mass shifts of 98 or $80 \mathrm{Da}$ both for $\mathrm{N}$ - and C-terminal fragments (b- and y-type ions) [26]. Owing to the labile nature of phosphate and sulfate ester groups, complete elimination of the modifications from the corresponding fragments is frequently observed under typical collisional activation conditions, which precludes pinpointing the modification sites. Alternatively, ECD and ETD of multiply charged phosphopeptide ions can produce extensive backbone fragmentation with preservation of phosphate groups [27-30], which greatly enhances the characterization process. Studies on ECD and ETD of sulfopeptides also show promise in sequencing and characterization, although a certain degree of sulfate loss is reported [31].

Atmospheric pressure thermal dissociation (APTD) represents a novel method for fragmentation of proteins and peptides ions and is performed outside the mass spectrometer [32]. Peptide ions generated by electrosonic spray ionization (ESSI) [33] or another ionization method are carried through a heated coiled metal tube where they fragment. Extensive fragmentation is typically obtained with this method, which makes it attractive for peptide/protein primary sequence elucidation. More importantly, neutral fragments arising from APTD can be characterized by on-line corona discharge ionization, providing complementary structural information that is not easily accessible via dissociation methods conducted in vacuum. Neutralizationreionization mass spectrometry (NRMS) experiments in vacuum require special instrumentation; they have proven to be a valuable source of information on molecular structure, especially on the existence of exotic neutral molecules [34-36]. Motivated by these earlier observations, APTD and subsequent neutral reionization (NRI) was applied to several standard peptides with PTMs, i.e., phosphorylation and sulfation. The fragmentation patterns of these peptides under APTD conditions were systematically studied and compared with those recorded using ion trap collision-induced dissociation. Improved primary structure information was generally observed from APTD by analyzing ionic and neutral fragments. Localization of the modification sites was achieved for phospho- and sulfopeptides with high confidence by combining the structure information acquired from APTD and CID.

\section{Experimental}

\section{Materials}

Peptides were purchased from different companies (AnaSpec, San Jose, CA; Biomol International, Plymouth Meeting, PA; Peptide International, Louisville, KY) and used without purification. The peptides are referred to by number and their single letter sequences are given in Tables 1 and 2. For samples examined in the positive ion mode, the peptides were typically prepared as a $0.1 \mathrm{mg} / \mathrm{mL}$ in 50:50 methanol/water solution containing $0.1 \%$ acetic acid. For negative ion- ization mode, $0.1 \%$ ammonium hydroxide was added to $0.1 \mathrm{mg} / \mathrm{mL}$ peptide solutions in 50:50 methanol/water.

\section{Mass Spectrometry}

All experiments were performed using an LTQ mass spectrometer (Thermo Fisher, San Jose, CA) fitted with a heated transfer capillary atmospheric pressure interface. The apparatus used for ion generation and thermal dissociation at atmospheric pressure consisted of an ESSI source and a stainless steel tube coiled to form two loops wrapped with heating tape, as described previously [32]. The fused silica capillary of the ESSI source was inserted into the mouth of the coiled tube, the exit of which was placed about $1 \mathrm{~cm}$ away from the inlet to the transfer capillary of the mass spectrometer. The temperature of the coiled tube was controlled by adjusting the voltage applied to the heating tape and monitored at the outer wall of the tube using an Omega thermocouple sensor (OMEGA Engineering, Stamford, $\mathrm{CT}$ ). The tube temperature ranged from 30 to $450{ }^{\circ} \mathrm{C}$. The peptide solutions were sprayed using a nebulizer gas pressure of 175 psi and the solution flow rate was fixed at $10 \mu \mathrm{L} / \mathrm{min}$ for all experiments. The ESSI source voltage was set at $+5 \mathrm{kV}$ or $-5 \mathrm{kV}$ for ionization in the positive or negative ion mode, respectively. The resulting thermally generated fragment ions emerging from the heated tube were mass analyzed using the LTQ mass spectrometer. The neutral reionization (NRI) experiments employed a pair of parallel metal plates as an "ion switch" to remove all charged species carried in the gas stream before the reionization step. One plate was grounded while the other was supplied with a potential bias of $-3 \mathrm{kV}$ to deflect all ions as monitored by the LTQ mass spectrometer. Neutral fragments were ionized via atmospheric pressure ionization (API) [37] by placing a corona discharge needle between the metal plates and the transfer capillary of the LTQ mass spectrometer. NRI mass spectra were recorded with a $+4 \mathrm{kV}$ or $-4 \mathrm{kV}$ voltage (depending on whether the positive or negative ionization mode was chosen) applied to the corona discharge needle while the ESSI gas stream passed through the ion switch. Different combinations of ESSI source polarity and corona discharge polarity were used to record a family of NRI mass spectra, i.e., $[+-],[++],[-+]$ and $[--]$. The first sign in the brackets represents the ion polarity for APTD, while the second sign is the ionization polarity for API. Not all these spectra were recorded for every chemical system. The nomenclature used for peptide ions is the standard nomenclature proposed by Roepstorff and Fohlman [38].

\section{Results and Discussion}

\section{Phosphopeptides}

The fragmentation pattern of the ESSI formed phosphopeptide (Peptide 1, single letter sequence: EPQ-pY- 


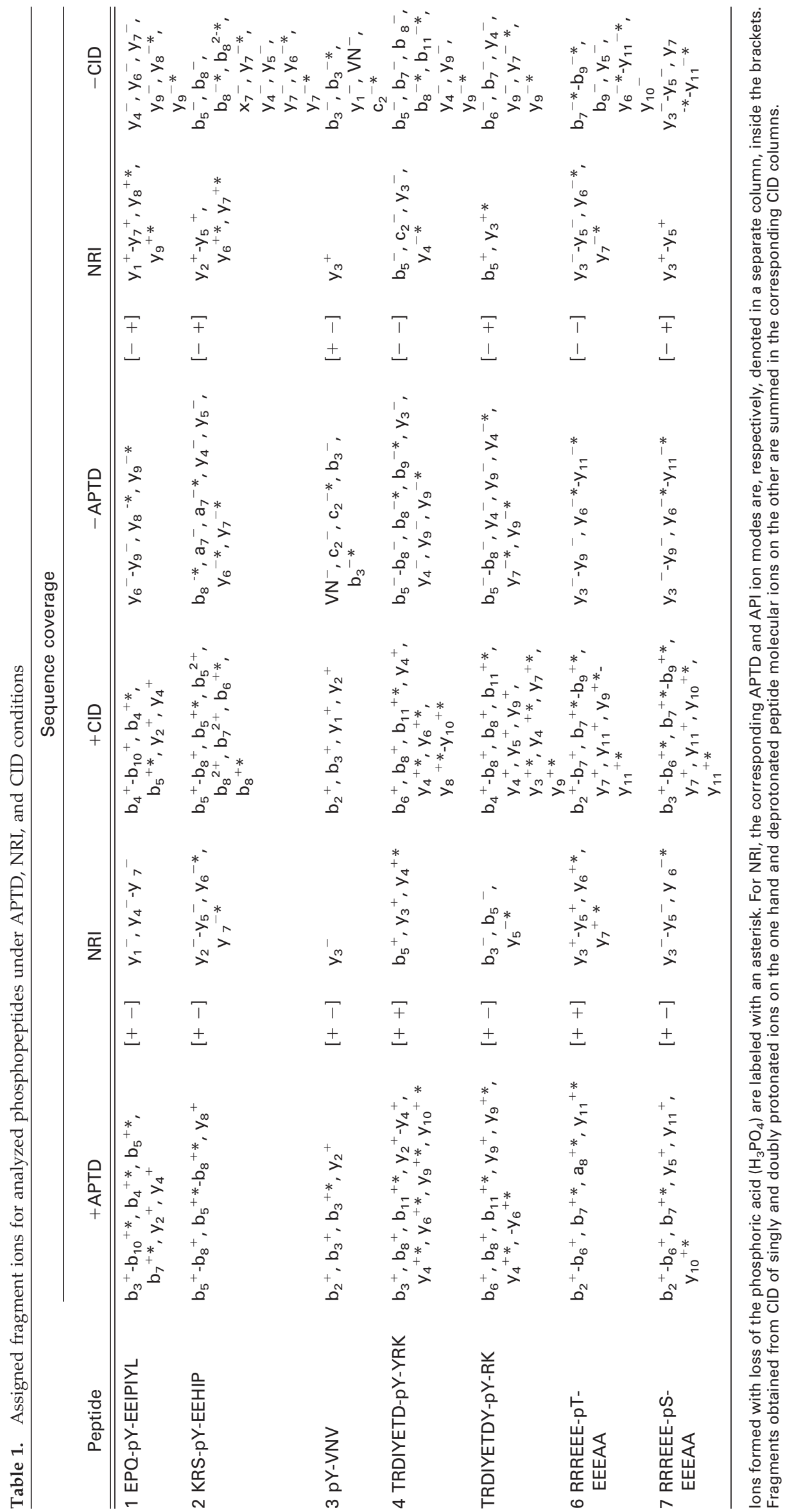


Table 2. Assigned fragment ions for analyzed sulfopeptides under APTD, NRI, and CID conditions

Sequence coverage

\begin{tabular}{|c|c|c|c|c|c|c|}
\hline Peptide & -APTD & & NRI & & NRI & $-\mathrm{CID}$ \\
\hline 8 FDMWGT-sY-DOE & $\mathrm{y}_{8}^{-*}-\mathrm{H}_{2} \mathrm{O}, \mathrm{c}_{7}^{-}, \mathrm{c}_{7}^{-*}$ & {$[--]$} & $\begin{array}{c}\mathrm{c}_{1}{ }^{-} \mathrm{c}_{6}^{-}, \mathrm{c}_{7}^{-*} \mathrm{y}_{2}{ }^{-}, \mathrm{y}_{3}{ }^{-}, \\
\mathrm{y}_{4}^{-*}, \mathrm{y}_{5}{ }^{-*}, \mathrm{y}_{8}{ }^{-*}\end{array}$ & {$[-+]$} & $\begin{array}{c}\mathrm{c}_{1}{ }^{+}-\mathrm{c}_{6}{ }^{+}, \mathrm{c}_{7}{ }^{+*} \mathrm{y}_{2}{ }^{+}, \mathrm{y}_{3}{ }^{+}, \\
\mathrm{y}_{4}{ }^{+*}, \mathrm{y}_{5}{ }^{+*}, \mathrm{y}_{8}{ }^{+*}\end{array}$ & $\begin{array}{c}\mathrm{y}_{8}^{-*}{ }_{-\mathrm{H}_{2} \mathrm{O}, \mathrm{C}_{7}^{-}}, \\
\mathrm{C}_{7}{ }^{-*}\end{array}$ \\
\hline 9 FDMWGM-sY-D & $\begin{array}{l}b_{5}^{-*}, y_{6}^{-}, y_{7}^{-} \\
y_{6}^{-*}\end{array}$ & {$[--]$} & $c_{2}^{-}-c_{6}^{-}, c_{7}^{-*}, y_{5}^{-}-y_{8}^{-*}$ & {$[-+]$} & $\mathrm{c}_{2}^{+}-\mathrm{c}_{6}{ }^{+}, \mathrm{c}_{7}^{+*} \mathrm{y}_{5}^{+}-\mathrm{y}_{8}^{+*}$ & $\begin{array}{c}\mathrm{b}_{2}^{-}, \mathrm{y}_{7}^{-}, \mathrm{y}_{7}^{-*}, \\
\mathrm{y}_{6}^{-}, \mathrm{y}_{6}^{-*}\end{array}$ \\
\hline
\end{tabular}

Ions formed with combined $\mathrm{SO}_{3}$ and $\mathrm{H}_{2} \mathrm{O}$ losses are labeled with an asterisk. For NRI, the corresponding APTD and API ion modes are denoted inside the brackets. Fragments obtained from CID of singly and doubly deprotonated peptide molecular ions are summed in the -CID column.

EEIPIYL) was studied using both APTD and ion trap CID. The neutral fragments induced by APTD were analyzed further using neutral reionization (NRI) as described previously [32]. The data acquired under these three modes are compared in Figure 1 for positively and negatively charged peptide ions, respectively. The fragment ions generated in the set of six experiments are also summarized in Table 1 for a variety of different conditions.

A range of temperatures $\left(30\right.$ to $450{ }^{\circ} \mathrm{C}$ ) was tested in the APTD experiments. Generally at temperatures below $200{ }^{\circ} \mathrm{C}$ little fragmentation was achieved, while complex spectra were observed at temperatures above $400{ }^{\circ} \mathrm{C}$ due to extensive fragmentation. Thus, the temperature on which the fragmentation had the highest yield together with limited secondary fragmentation was chosen to perform the APTD experiments, which was set at $350^{\circ} \mathrm{C}$. Upon APTD at $350{ }^{\circ} \mathrm{C}$, Peptide 1 (EPQ-pY-EEIPIYL) yields a main series of b-type ions in the positive ion mode and a series of y-type ions in the negative ion mode as shown in Figure 1a and d. In both modes, fragment ions that retain phosphate groups were detected together with those formed with losses of phosphate groups (denoted with an asterisk). This preservation of phosphate groups in APTD is remarkable, considering that the activation energy for $\mathrm{H}_{3} \mathrm{PO}_{4}$ loss is very low $(\sim 0.5 \mathrm{eV})[39,40]$ compared with that for peptide amide backbone cleavage $(\sim 1.2 \mathrm{eV})$ [41-43]. If the energy deposition from APTD were similar to thermal activation or IRMPD in vacuum, a preferred phosphoric acid loss should be observed with little backbone fragmentation or backbone fragmentation with phosphate group attached due to the slow heating nature of those methods [44]. The survival of phosphate groups therefore indicates that thermal activation of gas-phase ions is not the only activation mechanism in the APTD process. Some other activation processes that can deposit higher internal energy into peptide ions,

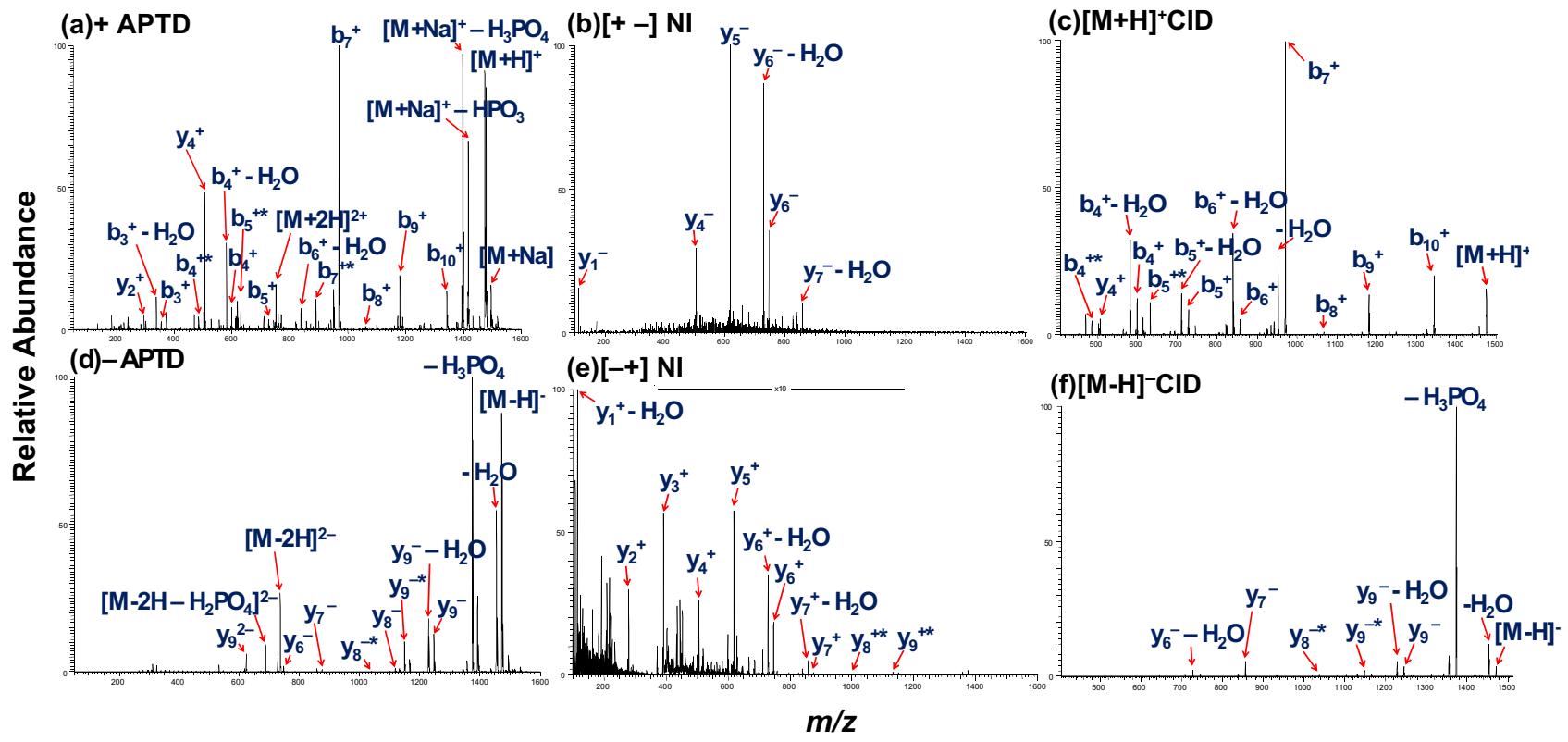

Figure 1. Mass spectra of the Peptide 1 (EPQ-pY-EEIPIYL) showing (a) APTD in the positive ion mode, (b) neutral species generated by positive ion mode APTD and ionized by API in the negative ion mode $([+-] \mathrm{NRI}) ;(\mathbf{c}) \mathrm{CID}$ of $[\mathrm{M}+\mathrm{H}]^{+}$ions in the positive ion mode; (d) APTD in the negative ion mode; (e) neutral species generated in negative ion mode APTD and ionized by API in the positive ion mode $([-+]$ $\mathrm{NRI}$ ); (f) CID of $[\mathrm{M}-\mathrm{H}]^{-}$ions in the negative mode. Ions formed with loss of the phosphoric acid group are labeled with an asterisk. 
such as collisions with the coiled tube surface leading to surface induced dissociation, might therefore play a role. At the same time, we are aware that ions might exist in microsolvated forms during some or all the APTD process, which could provide some degree of protection of the ions during activation.

The neutral species formed by thermal dissociation were ionized by API after emerging from the coiled tube. Figure $1 \mathrm{~b}$ shows the NRI mass spectrum arising from APTD in the positive ion mode and subsequently ionized in the negative ion mode by API, denoted as [ + - NRI in the figures and tables. A series of deprotonated y-type ions $\left(\mathrm{y}_{\mathrm{n}}{ }^{-}, n=1,4-7\right)$ is observed, complementary to the fragments observed in APTD (Figure 1a). The appearance of $\mathrm{y}_{4}$ ions in both the APTD and NRI spectra indicates they can be generated in both the ionic and corresponding neutral forms. The NRI spectrum recorded in the positive APTD and positive API mode $([++] \mathrm{NRI})$ provided the same y-type fragments as the $[+-]$ mode although in the protonated form, demonstrating the effectiveness of API for peptide neutral fragment reionization in either polarity. For that reason these data are not shown. The NRI mass spectrum was also obtained in the negative APTD and positive API $([-+]$ NRI) mode as shown in Figure 1e. Interestingly, some expected neutral fragments, e.g., b-type fragments, complementary to the APTD ionic products (Figure 1d), were not observed, while a series of y-type ions was detected. This observation suggests that under APTD conditions, dissociation of species other than completely desolvated ions in the gas phase, where complementary fragments are always encountered, may contribute. Another possibility is that $b$ fragments are not as stable as y fragments and can undergo further reactions during reionization. It is also noted that in NRI spectra the fragments formed with loss of the phosphate group are detected in greater abundance compared with those that preserve the phosphate groups in the ions directly observed from APTD. This may be because corona discharge is not soft enough to preserve the phosphate groups during ionization [45]. Although this feature prevents the confident use of neutral fragment ionized by API to characterize phosphorylation sites on a peptide, the rich fragment information obtained from NRI spectra is still very useful for primary structure elucidation as discussed later.

Ion trap collision-induced dissociation was applied to study the fragmentation of singly and doubly protonated and also deprotonated peptide molecular ions. The fragments shown in the "+CID" and "-CID" columns of Table 1 are the summed fragment ions derived from both charge states for each ion polarity. Figures 1c and $\mathrm{f}$ display the ion trap CID spectra acquired for $[\mathrm{M}+\mathrm{H}]^{+}$and $[\mathrm{M}-\mathrm{H}]^{-}$ions of Peptide 1, respectively. The fragmentation induced by CID shows similar patterns to those obtained from APTD (comparing Figure $1 \mathrm{a}-\mathrm{c}$ and $1 \mathrm{~d}-\mathrm{f}$ ). Similar sequence coverage (the number of peptide amide bond cleavages) were obtained by CID and APTD of Peptide 1 in the positive or the negative ion mode. Combining the data from both techniques, 8 out of 10 possible $b$ ions were detected, together with 6 out of 10 possible y ions from fragments produced in both polarities, while an almost complete series of y ions (9 out 10) was detected in NRI. Since there is no lower limit on the mass range for ions generated outside an ion trap under APTD compared with the approximately one third low mass cut-off limit in ion trap CID [46], small ions, e.g., $\mathrm{y}_{1}$, can be observed and this increases the coverage of fragment ions.

To localize the PTM site in a peptide, it is important to observe as many as possible of the peptide backbone fragments that bracket the potential modification sites. In the case of Peptide 1 (EPQ-pY-EEIPIYL), observation of $\mathrm{y}_{1}, \mathrm{y}_{2}, \mathrm{y}_{7}$, and $\mathrm{y}_{8}\left(\mathrm{y}_{8}{ }^{*}\right)$, as well as $\mathrm{b}_{3}, \mathrm{~b}_{4},\left(\mathrm{~b}_{4}{ }^{*}\right), \mathrm{b}_{9}$, and $b_{10}$ is desirable since either $\operatorname{Tyr}^{4}$ or $\operatorname{Tyr}^{10}$ could be phosphorylated. The positive ion mode data from APTD and CID provided the necessary $b$ ions, which established the phosphorylation site as $\mathrm{Tyr}^{4}$. The pair of $\mathrm{y}_{8}{ }^{-}\left(\mathrm{y}_{8}{ }^{-*}\right)$ peaks with a mass difference of $98 \mathrm{Da}$ was detected only by APTD in the negative ion mode. Negative mode CID yielded similar fragment ions but the ion $\mathrm{y}_{8}{ }^{-*}$ was seen without the corresponding presence of $\mathrm{y}_{8}{ }^{-}$. Additional information about the phosphorylation site can also be obtained with NRI since the ions $y_{1}$ and $y_{2}$, which are important to evaluate the phosphorylation at $\mathrm{Tyr}^{10}$, are only seen by $[-+]$ NRI. Thus, by combining the information from ionic and neutral fragments associated with APTD, all important ions needed to localize and cross-check the modification site are observed $\left(\mathrm{y}_{1}, \mathrm{y}_{2}, \mathrm{y}_{7}, \mathrm{y}_{8}, \mathrm{y}_{8}{ }^{*}, \mathrm{~b}_{3}, \mathrm{~b}_{4}, \mathrm{~b}_{4}{ }^{*}, \mathrm{~b}_{9}\right.$, and $b_{10}$ ). Therefore, it is possible to pinpoint the phosphorylation site with higher confidence than just using CID alone.

Another example in which APTD combined with NRI gives complementary information to CID for phosphopeptide fragmentation and localization of the modified site is Peptide 6 (RRREEE-pT-EEEAA). Figure 2 shows the fragmentation patterns of Peptide 6 recorded in the set of six spectra from APTD, NRI, and CID with the observed sequence ions being summarized in Table 1. Only one of the reionization polarity, i.e., $[++]$ and [- - ] NRI data are considered for the reasons given previously. In the positive ion mode, APTD and CID yield similar sequence ions containing both $b$ - and y-types of ions, while the relative abundance of the fragments is greater in APTD. The corresponding neutrals (Figure 2b) from positive APTD show mainly $\mathrm{y}$-type fragments, ranging from $\mathrm{y}_{3}$ to $\mathrm{y}_{7}$. In the negative ion mode, collision activation of the $[\mathrm{M}-\mathrm{H}]^{-}$ions yields both $b$ - and $y$-types of ions. Negative mode APTD, however, gives rise to a full series of y ions from $\mathrm{y}_{3}$ to $\mathrm{y}_{11}$, while the resulting neutrals consist of fragments from $\mathrm{y}_{3}$ to $\mathrm{y}_{7}$ as shown in Figure 2e. To localize the phosphorylation site in Peptide 6 (RRREEE-pTEEEAA), it is necessary to observe $y_{5}, y_{6}\left(y_{6}^{*}\right), b_{6}$, and $b_{7}$ $\left(b_{7}^{*}\right)$ fragments. While both CID and APTD yield fragments $\mathrm{y}_{5}, \mathrm{y}_{6}{ }^{*}$ (negative ion mode), and $\mathrm{b}_{6}, \mathrm{~b}_{7}^{*}$ (positive 


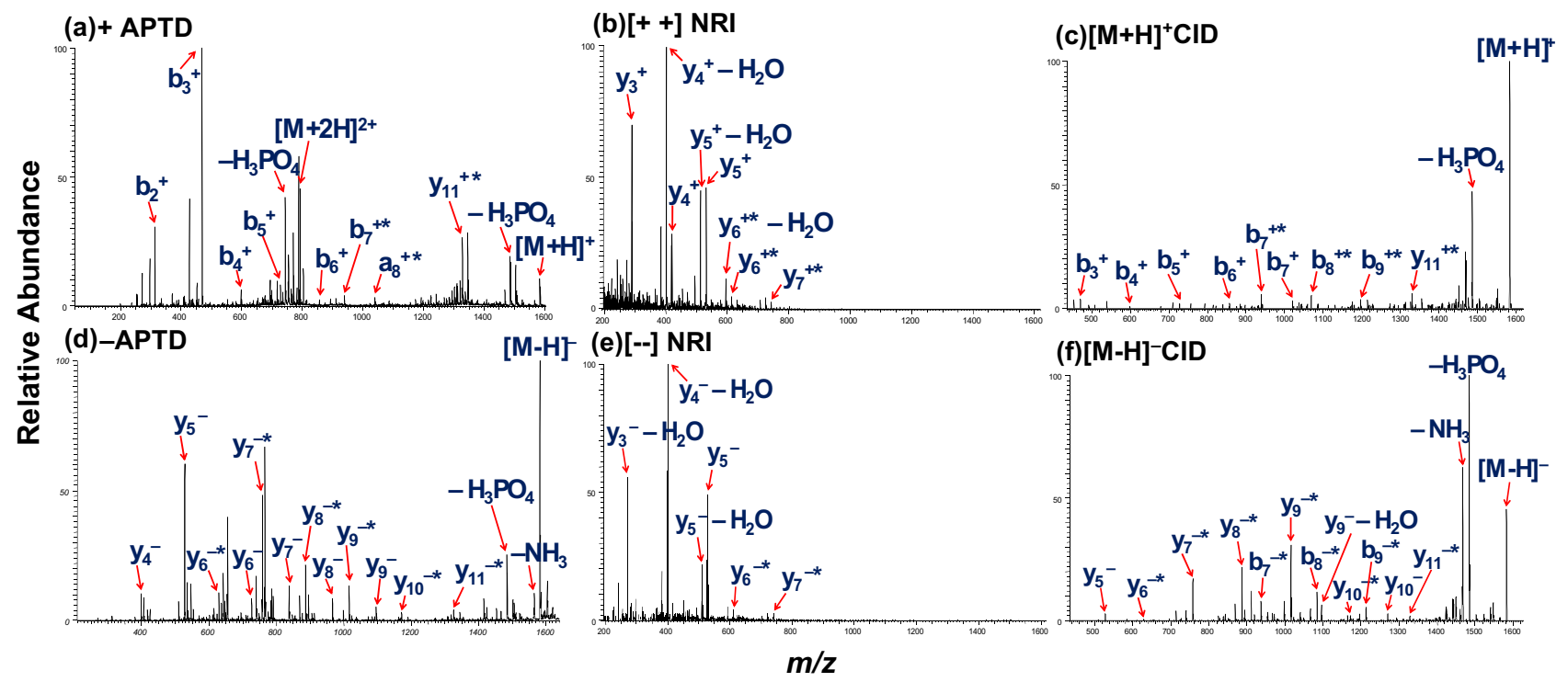

Figure 2. Mass spectra of the Peptide 6 (RRREEE-pT-EEEAA) showing (a) APTD in the positive ion mode; (b) neutral species generated by positive ion mode APTD and ionized by API in the positive ion mode $([++] \mathrm{NRI}) ;(\mathbf{c})$ CID of $[\mathrm{M}+\mathrm{H}]^{+}$ions in the positive ion mode; (d) APTD in the negative ion mode; (e) neutral species generated in the negative ion mode APTD and ionized by API in the negative ion mode ([- - ] NRI); (f) CID of $[\mathrm{M}-\mathrm{H}]^{-}$ions in the negative mode. Ions formed with loss of the phosphoric acid group are labeled with an asterisk.

ion mode), the intact $b_{7}$ ions (with the phosphate group attached) are only generated by CID in the positive ion mode and the intact $\mathrm{y}_{6}$ ions are only observed by APTD in the negative ion mode. Thus, it is necessary to combine the information from both APTD and CID in this case to achieve phosphopeptide characterization with high confidence.

In addition to Peptides 1 and 6, another five phosphopeptides containing either Tyr or Ser phosphorylation were subjected to APTD, subsequent NRI, and ion trap CID. The sequence information is summarized in Table 1. For all the phosphopeptides studied, abundant peptide backbone fragments were generally observed independent of the ionization polarity under APTD conditions. Rich sequence information can be obtained by analyzing both the ionic and neutral fragments resulting from APTD, which often complements and exceeds that obtained from CID alone. In addition, by combining the fragmentation information from APTD and CID, characterization of the phosphorylation sites can be achieved with high confidence. In the case of NRI, similar spectra are obtained for a given APTD mode independent of reionization polarities. NRI is therefore considered as a soft-ionization technique, since no additional backbone fragmentation is observed, which is consistently observed for all phosphopeptides studied herein.

\section{Sulfopeptides}

Due to the low ion yield achieved in the positive ion ESSI mode, sulfopeptides were analyzed by CID and APTD only in the negative ion mode, while NRI exper- iments were performed in the negative APTD mode combined with API in both the positive and negative ion modes. Figure $3 a$ and $b$ show APTD and ion trap CID mass spectra of Peptide 8 (FDMWGT-sY-DQE) in the negative ion mode, respectively. From both activation methods, the predominant fragmentation channels are the loss of $\mathrm{SO}_{3}$ and combined losses of $\mathrm{SO}_{3}$ and $\mathrm{H}_{2} \mathrm{O}$ from $[\mathrm{M}-\mathrm{H}]^{-}$ions. Backbone fragment ions such as $\mathrm{y}_{9}{ }^{-*}$ and the $\mathrm{C}_{7}^{-} /\left(\mathrm{c}_{7}{ }^{-}-\mathrm{SO}_{3}\right)$ pair are apparent in the APTD spectrum (asterisk denotes ions formed with combined $\mathrm{SO}_{3}$ and $\mathrm{H}_{2} \mathrm{O}$ losses). While the same set of ions is detected in CID, the relative abundances are greatly reduced compared to APTD. Good coverage for the peptide amino acid sequence is not obtained by any of the dissociation techniques. The formation of $\mathrm{C}_{7}{ }^{-}$ions is expected since it is common for deprotonated peptides containing aspartic acid to undergo a fragmentation reaction involving nominal cleavage of the $\mathrm{N}-\mathrm{C} \alpha$ bond $\mathrm{N}$-terminal to the aspartic acid residue to form the $\mathrm{c}$ ion and the complementary product [47]. The neutral fragments generated from negative APTD were analyzed in positive and negative mode API, as shown in Figure $3 c$ and $d$, respectively. Abundant fragments were observed, including $\mathrm{c}_{n}(n=1-7)$ and $\mathrm{y}_{n}(n=2-5$, 9 ) ions. Note that the fragments which should have sulfono-moiety were detected with loss of $\mathrm{SO}_{3}$ or combined losses of $\mathrm{SO}_{3}$ and $\mathrm{H}_{2} \mathrm{O}$.

The assigned $\mathrm{c}$ ions from NRI were subjected to ion trap collisional activation for structure elucidation. Amide bond cleavages were generally observed giving rise to new $\mathrm{b}$ - and $\mathrm{y}$ ions, consistent with literature reports on CID of c-type ions [48, 49]. The assignments can also be validated by comparing the CID data of the 


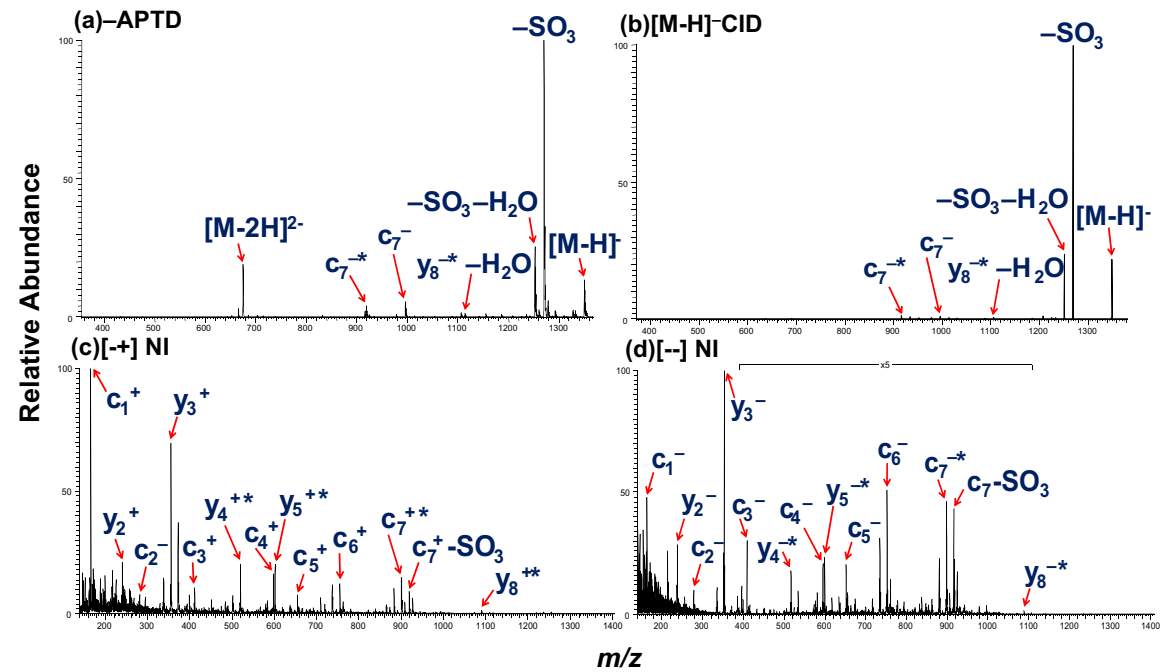

Figure 3. Mass spectra of Peptide 8 (FDMWGT-sY-DQE) showing (a) negative ion mode APTD, (b) $\mathrm{CID}$ of $[\mathrm{M}-\mathrm{H}]^{-}$ions, (c) neutral species generated from negative ion mode APTD and ionized by API in the positive ion mode ([- + ] NRI), and (d) neutral species generated from negative ion mode APTD and ionized by API in the negative mode ([-- ] NRI). Ions formed with combined losses of $\mathrm{SO}_{3}$ and $\mathrm{H}_{2} \mathrm{O}$ are labeled with an asterisk.

presumed $\mathrm{c}$ ions and the C-amidated peptides, which share the same sequences and therefore have the same structures as the c ions. Figure $4 \mathrm{a}$ and $\mathrm{b}$ compare ion trap CID data of $[\mathrm{M}+\mathrm{H}]^{+}$ions of $\mathrm{C}$-amidated phenylalanine formed by positive ESSI, with the assigned $\mathrm{c}_{1}{ }^{+}$ ions from neutral reionization. The exact same dissoci-

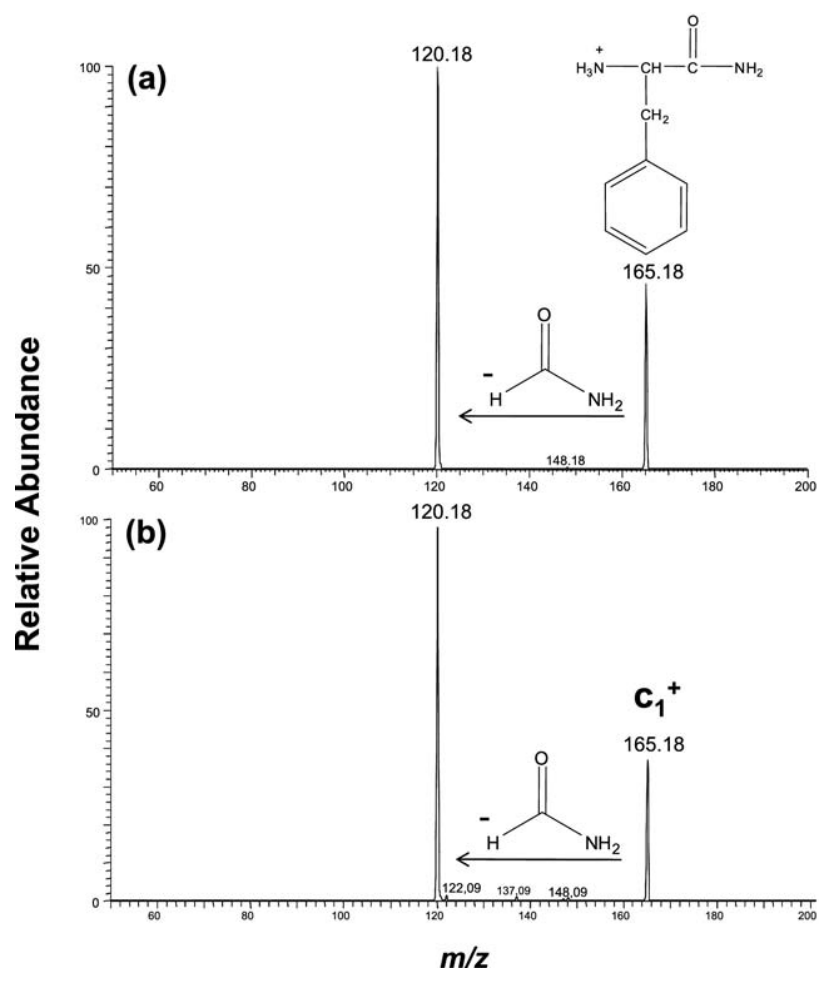

Figure 4. Mass spectra showing (a) CID of protonated Camidated phenylalanine $(\mathrm{m} / \mathrm{z} 165)$ and (b) CID of the assigned $\mathrm{c}_{1}{ }^{+}$ion obtained from $[-+]$ NRI of peptide caerulein. ation pattern (loss of formamide, $45 \mathrm{Da}$ ) strongly suggests the similarity in structure between the two species and further supports the $c$ ion assignment. Although it is rare to observe $c$ ions upon collisional activation of protonated peptides, it is not uncommon for deprotonated peptide ions, where several pathways can contribute to the formation of $\mathrm{c}$ ions, especially in the presence of aspartic acid residues [50, 51].

The fragment ions of Peptide 8 obtained by CID, APTD, and NRI are summarized in Table 2. It is not surprising that the backbone fragmentation in CID is largely suppressed, while $\mathrm{SO}_{3}$ loss, the most facile fragmentation channel dominates, considering the slow heating nature of ion trap collisional activation [44]. (See, however, the earlier arguments regarding dephosphorylation indicate that the process is somewhat more complex). In the case of APTD, the backbone fragments are more abundant than those formed by ion trap CID. This phenomenon is consistently observed for all the peptides studied here, which may be due to higher energy deposition during activation. Although thermal activation plays a significant role in APTD, activation due to surface collisions similar to SID cannot be excluded. Nevertheless, the sequence coverage for the Peptide 8 is not improved by just analyzing the ions (two sequence ions) directly formed in APTD. As a major contrast, when the neutrals produced from APTD are analyzed, eleven sequence fragments are obtained. Clearly, NRI coupled with APTD maximizes the retrieval of sequence information from Peptide 8. To localize the post-translational modification site in Peptide 8 (FDMWGT-sY-DQE), it is important to verify the ions formed near residues $\mathrm{Thr}^{6}$ and $\mathrm{Tyr}^{7}$, since either of the two residues can be sulfated [22]. APTD data provided the pairs of $c_{7}$ peaks with a mass difference of 
$80 \mathrm{Da}$, which suggests a modification site at either $\mathrm{Thr}^{6}$ or $\mathrm{Tyr}^{7}$. In NRI data, the observation of a series of $y$ ions and a 98 Da loss started from $\mathrm{y}_{4}$ ions (at the N-terminal side of $\mathrm{Tyr}^{7}$ ) allows pinpointing the modification site as $\mathrm{Tyr}^{7}$ instead of Thr ${ }^{6}$. Therefore, by combining the information of ions and neutrals generated from thermal dissociation, sequencing and characterizing peptide with a labile modification, such as sulfation, is possible.

Another sulfopeptide, Peptide 9 (FDMWGM-sY-D) was also studied by APTD, subsequent NRI, and CID. The fragments observed under each condition are summarized in Table 2. Several b- and y-type of ions were identified in APTD and CID. As observed for Peptide 8 (FDMWGT-sY-DQE), the intensities of the sequence ions were largely suppressed due to abundant neutral losses (loss of 80 and $98 \mathrm{Da}$ ). On the other hand, an almost complete series of $c$ ions was observed in NRI, allowing facile sequencing of this peptide. Also note that the same identities of a set of fragment ions are produced by reionization in positive and negative ion modes of a particular APTD polarity for both sulfopeptides. Although the sulfopeptides studied herein are quite limited, the rich sequence informative data obtained from NRI warrants further studies of other sulfopeptides to determine the generality of the observations made in this work.

\section{Conclusions}

The results of this work show that rich information on amino acid primary sequence and PTM sites can be obtained for phospho- and sulfopeptides by analyzing both ionic and neutral species generated from APTD. The sequence information acquired from APTD when combined with NRI often complements and exceeds that obtained from ion trap collisional activation alone. A combination of the information from APTD and CID allows characterization of the modified peptides with higher confidence. The neutral fragments arising from APTD occur with losses of the modification sites. Although this feature prevents direct use in characterizing the modification sites, the rich sequence information that NRI coupled with APTD provides is still very valuable for peptide sequencing. The importance and necessity of analyzing neutral fragments is highlighted by the data of sulfopeptides, where sequence-specific fragment ions are largely suppressed due the presence of facile neutral loss channels. The promising results noted for APTD coupled with NRI warrant their further exploration as a tool to study the fragmentation patterns of post-translationally modified peptides. A followup study to replace neutral fragment ionization using API by softer ionization with extractive electrospray ionization (EESI) [52], which might lead to observation of neutral fragments with preserved labile modifications, is under way.

\section{Acknowledgments}

The authors acknowledge funding of this research by the National Science Foundation (CHE-0412782).

\section{References}

1. Aebersold, R.; Goodlett, D. R. Mass Spectrometry in Proteomics. Chem. Rev. 2001, 101, 269-295.

2. Wells, J. M.; McLuckey, S. A. Collision-Induced Dissociation (CID) of Peptides and Proteins. Methods Enzymol. 2005, 402, 148-185.

3. Dongre, A. R.; Somogyi, A.; Wysocki, V. H. Surface-Induced Dissociation: An Effective Tool to Probe Structure, Energetics, and Fragmentation Mechanisms of Protonated Peptides. J. Mass Spectrom. 1996, 31, 339-350.

4. Little, D. P.; Speir, J. P.; Senko, M. W.; O'Connor, P. B.; McLafferty, F. W. Infrared Multiphoton Dissociation of Large Multiply Charged Ions for Biomolecule Sequencing. Anal. Chem. 1994, 66, 2809-2815.

5. Woodin, R. L.; Bomse, D. S.; Beauchamp, J. L. Multi-Photon Dissociation of Molecules with Low-Power Continuous Wave Infrared-Laser Radiation. J. Am. Chem. Soc. 1978, 100, 3248-3250.

6. Price, W. D.; Schnier, P. D.; Williams, E. R. Tandem Mass Spectrometry of Large Biomolecule Ions by Blackbody Infrared Radiative Dissociation. Anal. Chem. 1996, 68, 859-866.

7. Bowers, W. D.; Delbert, S. S.; Hunter, R. L.; McIver, R. T. Fragmentation of Oligopeptide Ions Using Ultraviolet-Laser Radiation and FourierTransform Mass-Spectrometry. J. Am. Chem. Soc. 1984, 106, 7288-7289.

8. Thompson, M. S.; Cui, W. D.; Reilly, J. P. Fragmentation of Singly Charged Peptide Ions by Photodissociation at $\lambda=157 \mathrm{~nm}$. Angew. Chem. Int. Ed. 2004, 43, 4791-4794.

9. Zubarev, R. A. Reactions of Polypeptide Ions with Electrons in the Gas Phase. Mass Spectrom. Rev. 2003, 22, 57-77.

10. Zubarev, R. A.; Kelleher, N. L.; McLafferty, F. W. Electron Capture Dissociation of Multiply Charged Protein Cations. A Nonergodic Process. J. Am. Chem. Soc. 1998, 120, 3265-3266.

11. Syka, J. E. P.; Coon, J. J.; Schroeder, M. J.; Shabanowitz, J.; Hunt, D. F. Peptide and Protein Sequence Analysis by Electron Transfer Dissociation Mass Spectrometry. Proc. Nat. Acad. Sci. U.S.A. 2004, 101, 95289533.

12. Coon, J. J.; Syka, J. E. P.; Schwartz, J. C.; Shabanowitz, J.; Hunt, D. F. Anion Dependence in the Partitioning between Proton and Electron Transfer in Ion/Ion Reactions. Int. J. Mass Spectrom. 2004, 236, 33-42.

13. Mann, M.; Jensen, O. N. Proteomic Analysis of Post-Translational Modifications. Nat. Biotechnol. 2003, 21, 255-261.

14. Hunter, T. Signaling-2000 and Beyond. Cell 2000, 100, 113-127.

15. Manning, G.; Whyte, D. B.; Martinez, R.; Hunter, T.; Sudarsanam, S. The Protein Kinase Complement of the Human Genome. Science 2002, 298, 1912-1934.

16. Marks, F. Protein Phosphorylation; VCH: Weinheim, 1996.

17. Kehoe, J. W.; Bertozzi, C. R. Tyrosine Sulfation: A Modulator of Extracellular Protein-Protein Interactions. Chem. Biol. 2000, 7, R57-R61.

18. Garcia, B. A.; Shabanowitz, J.; Hunt, D. F. Analysis of Protein Phosphorylation by Mass Spectrometry. Methods 2005, 35, 256-264.

19. Carr, S. A.; Annan, R. S.; Huddleston, M. J. Mapping Posttranslational Modifications of Proteins by MS-Based Selective Detection: Application to Phosphoproteomics. Methods Enzymol. 2005, 405, 82-115.

20. Nemeth-Cawley, J. F.; Karnik, S.; Rouse, J. C. Analysis of Sulfated Peptides Using Positive Electrospray Ionization Tandem Mass Spectrometry. J. Mass Spectrom. 2001, 36, 1301-1311.

21. Wolfender, J. L.; Chu, F. X.; Ball, H.; Wolfender, F.; Fainzilber, M.; Baldwin, M. A.; Burlingame, A. L. Identification of Tyrosine Sulfation in Conus pennaceus Conotoxins $\alpha$-PnIA and $\alpha$-PnIB: Further Investigation of Labile Sulfo- and Phosphopeptides by Electrospray, Matrix-Assisted Laser Desorption/Ionization (MALDI), and Atmospheric Pressure MALDI Mass Spectrometry. J. Mass Spectrom. 1999, 34, 447-454.

22. Medzihradszky, K. F.; Darula, Z.; Perlson, E.; Fainzilber, M.; Chalkley, R. J.; Ball, H.; Greenbaum, D.; Bogyo, M.; Tyson, D. R.; Bradshaw, R. A. Burlingame, A. L. O-Sulfonation of Serine and Threonine-Mass Spectrometric Detection and Characterization of a New Post-Translational Modification in Diverse Proteins Throughout the Eukaryotes. Mol. Cell. Proteom. 2004, 3, 429-440.

23. Huddleston, M. J.; Annan, R. S.; Bean, M. F.; Carr, S. A. Selective Detection of Phosphopeptides in Complex-Mixtures by Electrospray Liquid-Chromatography Mass-Spectrometry. J. Am. Soc. Mass Spectrom. 1993, 4, 710-717.

24. Annan, R. S.; Huddleston, M. J.; Verma, R.; Deshaies, R. J.; Carr, S. A. A Multidimensional Electrospray MS-Based Approach to Phosphopeptide Mapping. Anal. Chem. 2001, 73, 393-404.

25. Olsen, J. V.; Blagoev, B.; Gnad, F.; Macek, B.; Kumar, C.; Mortensen, P.; Mann, M. Global, in Vivo, and Site-Specific Phosphorylation Dynamics in Signaling Networks. Cell 2006, 127, 635-648.

26. Kinter, M.; Sherman, N. E. Protein Sequencing and Identification Using Tandem Mass Spectrometry; John Wiley: Chichester, 2000.

27. Stensballe, A.; Jensen, O. N.; Olsen, J. V.; Haselmann, K. F.; Zubarev, R. A. Electron Capture Dissociation of Singly and Multiply Phosphorylated Peptides. Rapid Commun. Mass Spectrom. 2000, 14, 1793-1800. 
28. Shi, S. D. H.; Hemling, M. E.; Carr, S. A.; Horn, D. M.; Lindh, I.; McLafferty, F. W. Phosphopeptide/Phosphoprotein Mapping by Electron Capture Dissociation Mass Spectrometry. Anal. Chem. 2001, 73, $19-22$.

29. Coon, J. J.; Ueberheide, B.; Syka, J. E. P.; Dryhurst, D. D.; Ausio, J.; Shabanowitz, J.; Hunt, D. F. Protein Identification Using Sequential Ion/Ion Reactions and Tandem Mass Spectrometry. Proc. Nat. Acad. Sci. U.S.A. 2005, 102, 9463-9468.

30. Gunawardena, H. P.; Emory, J. F.; McLuckey, S. A. Phosphopeptide Anion Characterization Via Sequential Charge Inversion and ElectronTransfer Dissociation. Anal. Chem. 2006, 78, 3788-3793.

31. Medzihradszky, K. F.; Guan, S.; Maltby, D. A.; Burlingame, A. L. Sulfopeptide Fragmentation in Electron-Capture and Electron-Transfer Dissociation. J. Am. Soc. Mass Spectrom. 2007, 18, 1617-1624

32. Chen, H.; Eberlin, L. S.; Cooks, R. G. Neutral Fragment Mass Spectra via Ambient Thermal Dissociation of Peptide and Protein Ions. J. Am. Chem. Soc. 2007, 129, 5880-5886.

33. Takats, Z.; Wiseman, J. M.; Gologan, B.; Cooks, R. G. Electrosonic Spray Ionization. A Gentle Technique for Generating Folded Proteins and Protein Complexes in the Gas Phase and for Studying Ion-Molecule Reactions at Atmospheric Pressure. Anal. Chem. 2004, 76, 4050-4058.

34. Wesdemiotis, C.; Mclafferty, F. W. Neutralization Reionization MassSpectrometry (NRMS). Chem. Rev. 1987, 87, 485-500.

35. Schalley, C. A.; Hornung, G.; Schroder, D.; Schwarz, H. Mass Spectrometric Approaches to the Reactivity of Transient Neutrals. Chem. Soc. Rev. 1998, 27, 91-104.

36. Tureček, F. Transient Intermediates of Chemical Reactions by Neutralization-Reionization Mass Spectrometry. Top. Curr. Chem. 2003, 225, 77-129.

37. Bruins, A. P. Mass-Spectrometry with Ion Sources Operating at Atmospheric-Pressure. Mass Spectrom. Rev. 1991, 10, 53-77.

38. Roepstorff, P.; Fohlman, J. Proposal for a Common Nomenclature for Sequence Ions in Mass-Spectra of Peptides. Biomed. Mass Spectrom. 1984, 11, 601-601.

39. Flora, J. W.; Muddiman, D. C. Determination of the Relative Energies of Activation for the Dissociation of Aromatic versus Aliphatic Phosphopeptides by ESI-FTICR-MS and IRMPD. J. Am. Soc. Mass Spectrom. 2004, 15, 121-127.

40. Gronert, S.; Li, K. H.; Horiuchi, M. Manipulating the Fragmentation Patterns of Phosphopeptides Via Gas-Phase Boron Derivatization: Determining Phosphorylation Sites in Peptides with Multiple Serines. J. Am. Soc. Mass Spectrom. 2005, 16, 1905-1914.
41. Meotner, M.; Dongre, A. R.; Somogyi, A.; Wysocki, V. H. ThermalDecomposition Kinetics of Protonated Peptides and Peptide Dimers, and Comparison with Surface-Induced Dissociation. Rapid Commun. Mass Spectrom. 1995, 9, 829-836.

42. Butcher, D. J.; Asano, K. G.; Goeringer, D. E.; McLuckey, S. A. Thermal Dissociation of Gaseous Bradykinin Ions. J. Phys. Chem. A 1999, 103, 8664-8671.

43. Busman, M.; Rockwood, A. L.; Smith, R. D. Activation-Energies for Gas-Phase Dissociations of Multiply Charged Ions from Electrospray Ionization Mass-Spectrometry. J. Phys. Chem. 1992, 96, 2397-2400.

44. McLuckey, S. A.; Goeringer, D. E. Slow Heating Methods in Tandem Mass Spectrometry. J. Mass Spectrom. 1997, 32, 461-474.

45. Cristoni, S.; Bernardi, L. R.; Biunno, I.; Guidugli, F. Analysis of Peptides Using Partial (No Discharge) Atmospheric Pressure Chemical Ionization Conditions with Ion Trap Mass Spectrometry. Rapid Commun. Mass Spectrom. 2002, 16, 1686-1691.

46. Louris, J. N.; Cooks, R. G.; Syka, J. E. P.; Kelley, P. E.; Stafford, G. C. Todd, J. F. J. Instrumentation, Applications, and Energy Deposition in Quadrupole Ion-Trap Tandem Mass-Spectrometry. Anal. Chem. 1987, $59,1677-1685$.

47. Harrison, A. G.; Young, A. B. Fragmentation Reactions of Deprotonated Peptides Containing Aspartic Acid. Int. J. Mass Spectrom. 2006, 255, 111-122.

48. Han, H. L.; Xia, Y.; McLuckey, S. A. Ion Trap Collisional Activation of $\mathrm{c}$ and $\mathrm{z}$ Ions Formed via Gas-Phase Ion/Ion Electron-Transfer Dissociation. J. Proteome Res. 2007, 6, 3062-3069.

49. Mouls, L.; Subra, G.; Aubagnac, J. L.; Martinez, J.; Enjalbal, C. Tandem Mass Spectrometry of Amidated Peptides. J. Mass Spectrom. 2006, 41, 1470-1483.

50. Bowie, J. H.; Brinkworth, C. S.; Dua, S. Collision-Induced Fragmentations of the $(\mathrm{M}-\mathrm{H})^{-}$Parent Anions of Underivatized Peptides: An Aid to Structure Determination and Some Unusual Negative Ion Cleavages. Mass Spectrom. Rev. 2002, 21, 87-107.

51. Boontheung, P.; Alewood, P. F.; Brinkworth, C. S.; Bowie, J. H. Wabnitz, P. A.; Tyler, M. J. Negative Ion Electrospray Mass Spectra of Caerulein Peptides: An Aid to Structural Determination. Rapid Commun. Mass Spectrom. 2002, 16, 281-286.

52. Chen, H. W.; Venter, A.; Cooks, R. G. Extractive Electrospray Ionization for Direct Analysis of Undiluted Urine, Milk, and Other Complex Mixtures without Sample Preparation. Chem. Commun. 2006, 2042-2044. 